\title{
Calculation and Construction of Load Diagrams and Static Characteristics of Multi-Motor Electric Drive System Using Methods of Equivalent Forces and Reduced Moments
}

\author{
M.N. Semenova ${ }^{1, *}$, I.A.Yakushev ${ }^{1}$, S.A. Zagolilo ${ }^{1}$, Ya.S. Kharitonov ${ }^{2}$, V.A. Shevchuk ${ }^{3}$, and I.V. Ivshin ${ }^{4}$ \\ ${ }^{1}$ North-Eastern Federal University n.a. M.K. Ammosov, Mirny Polytechnic Institute, 678170, Mirny, Russia \\ ${ }^{2}$ PJSC ALROSA, 678170, Mirny, Russia \\ ${ }^{3}$ JSC Research and Production Center Polyus, 634050, Tomsk, Russia \\ ${ }^{4}$ Kazan State Power Engineering University, str. Krasnoselskaya, 51, 420066, Kazan, Russia
}

\begin{abstract}
This paper includes the calculations and construction of load diagrams and static characteristics of individual mechanisms of a mining combine, which form a combined multi-motor electric drive system, using methods of equivalent efforts and reduced moments. The operating forces of idle and on-load mechanisms are calculated, operation time intervals and a complete working cycle are determined. The load diagrams of mechanisms are constructed and their kinematic diagrams are designed. Based on the calculations made, asynchronous motors with a short-circuit rotor, which have the closest power values and are suitable in terms of voltage and operating mode, were selected from the catalogue. The gear reduction ratio is calculated, static resistance moments and operating speeds to the motor shaft are specified. The static characteristics of the most powerful electric motor of a mining combine - effector - are formulated.
\end{abstract}

\section{Introduction}

Underground mineral deposits, namely diamond-bearing rocks, are now being actively developed in Western Yakutia [1, 2]. It is justified by economic expediency, since the cost of stripping works is reduced, less specialpurpose open-cut transport is required [3]. The issues of mechanization of loading of destroyed rock mass on the face conveyor or other vehicles are very important both in terms of ensuring a highly productive operation of the winning machine and for the purpose of facilitating working conditions of miners, since a manual loading of rock mass is rough labor taking place most often in the most dangerous, unsecured territories [4-6].

Mining combines are designed for preparatory horizontal excavation of ore deposits with different rockhardness ratios $\mathrm{f}$ in the range of $4-10$ on the scale of M.M. Protodiakonov. The main direction for the development of comprehensive mechanization of roadheading and mining operations is the introduction of a combining method of roadway construction, which reached $80 \%$ in 2018. Light and medium roadheaders (weighing from 20 to 100 tons with specific power of the effector ranging from 100 to $300 \mathrm{~kW}$ ), working with the rocks or soft rock cutting are mainly used. Heavy mining combines account for only about $20 \%$ [7].

Voest-Alpine Bergtechnik GesmbH (Austrian manufacturer of mining equipment) $\mathrm{AM}$ series medium and heavy mining combines with a weight of 30-80 tons and specific power of the effector ranging from 200 to $250 \mathrm{~kW}$ are mass-produced for the heading of rocks with a rock-hardness ratio $\mathrm{f} \geq 7$ and a cross-section area $\leq 50$ $\mathrm{m} 2$. Mining AM combines are self-propelled tracked machines with a boom-type effector and loading device in the form of paired pallet handles on the inclined rotary table with an independent drive [8].

\section{Relevance, research objective and tasks}

The stage of development of pit reserves through an auxiliary ventilation shaft, the size of which does not allow transporting the well-proven mining combine AM105 to a working face, started at one of underground mines in Western Yakutia where diamond-bearing rocks are mined. So, AM-75 mining combine was delivered to the mine in order to continue mining. The authors were interested in the multi-motor electric drive system of this complex and its energy performance. Since the mine is a gas and oil hazardous facility, it is not possible to simply "come" there and measure these figures. Thus, the authors decide to make the necessary calculations and construct the necessary diagrams using the methods of equivalent efforts and reduced moments.

Therefore, the purpose of this paper will be the calculation and construction of load diagrams and static characteristics of multi-motor electric drive system of a mining combine using the methods of equivalent forces and reduced moments. The following tasks will be completed in order to achieve this objective: operating forces of idle and on-load mechanisms will be

*Corresponding author: mariya semyonova86@mail.ru 
calculated; operation time intervals and a complete working cycle will be determined; load diagrams of mechanisms will be constructed and their kinematic diagrams will be designed; electric motors will be preselected on the basis of calculated parameters; gear reduction ratio will be calculated; static resistance moments and operating speeds to the motor shaft will be specified; static characteristics of electric motors of mechanisms of combine will be determined.

\section{Research results}

\subsection{Calculation of output capacity and combine selection}

The output capacity is obtained on the basis of mining capabilities and the economically viable life of the mine, as well as by mining capabilities, taking into account the dip angle of the deposit. At the angle of ore body dip over $30^{\circ}$, the annual output will be determined as follows:

$$
A_{g}=U \cdot K_{\mathbf{1}} \cdot K_{\mathbf{2}} \cdot K_{\mathbf{3}} \cdot K_{\mathbf{4}} \cdot S \cdot \rho \cdot \frac{1-W}{1-D},[t],
$$

where $U$ is the annual decrease of stoping over the entire ore area, m/year; $K_{1}, K_{2}, K_{3}, K_{4}$ are correction factors, which take into account, respectively, the dip angle, thickness of ore body, mining system the number of layers in simultaneous mining; $W$ and $D$ - are planned values of losses and ore dilution, unit fractions; $S$ - is a horizontal area of ore body, $\mathrm{m}^{2}$, determined from the expression: $S=m \cdot \frac{L_{p r}}{\sin \alpha}$.

Then define an hourly output capacity of the mine on the basis of the calculated annual output:

$$
A_{\boldsymbol{h}}=\frac{A_{g}}{N_{d} \cdot N_{\boldsymbol{h}}},\left[\frac{t}{h}\right],
$$

where $N_{d, h}$ - respectively the number of working days and hours.

Since the combine output capacity is set in $\mathrm{m}^{3} / \mathrm{min}$, obtain the hourly capacity of the combine:

$$
Q_{\text {harv } . h}=Q_{\text {harv.m }} \cdot 60,\left[\frac{m^{3}}{h}\right]
$$

When developing rock with a rock-hardness ratio $f>6$ take density $\rho=2.44 \mathrm{t} / \mathrm{m}^{3}$ and get:

$$
Q_{\text {harv.h }}=Q_{\text {harv } \cdot \boldsymbol{h}} \cdot \rho,\left[\frac{t}{h}\right]
$$

On the basis of the determined rate of production take two AM-75 combine with a specified minute capacity $Q=0,5 \mathrm{~m}^{3} / \mathrm{min}$. Next, the authors compile a table of the main parameters of the combine and its mechanisms, which are necessary for further calculation (Table 1).
Table 1.Technical specifications of AM-75 combine.

\begin{tabular}{|l|c|}
\hline \multicolumn{1}{|c|}{ Parameter name } & Value \\
\hline $\begin{array}{l}\text { Reference hourly productivity of the combine, } \\
Q_{\text {harv. } h}[\mathrm{t} / \mathrm{h}]\end{array}$ & 80 \\
\hline $\begin{array}{l}\text { The total power of the combine's electric } \\
\text { motors, } P_{\Sigma}[\mathrm{kW}]\end{array}$ & 350 \\
\hline $\begin{array}{l}\text { Diameter of the cutting head of the working } \\
\text { body, } D[\mathrm{~mm}]\end{array}$ & 750 \\
\hline $\begin{array}{l}\text { Width of the overhead bar of the working body, } \\
B[\mathrm{~mm}]\end{array}$ & 1000 \\
\hline Boom length of the working body, $L[\mathrm{~mm}]$ & 2500 \\
\hline Boom swing and tilt angle, $\alpha^{\circ}$ & 30 \\
\hline Combine weight, $W_{\text {harv }}[$ tones] & 52 \\
\hline
\end{tabular}

\subsection{Calculation and construction of load diagrams using the equivalent force method}

A preliminary selection of electric motors requires the construction of load diagrams of mechanisms (static load diagrams) $[9,10]$. The calculation of the cycle time at the motor pre-selection stage is approximate since it is not yet possible to obtain the acceleration and deceleration time (the total moment of inertia of the drive is unknown before selection of motor) $[11,12]$.

Calculate the parameters of the load diagram for the most powerful mechanism - the combine effector. Similarly obtained results for other mechanisms will be summarized in a table for the ease of construction of load diagrams [13-15].

Rotary force of idle combine's effector:

$$
F_{n \cdot l}=m_{w \cdot b} \cdot g \cdot \mu_{,}[N]
$$

where $\mu$ is the coefficient of friction of the effector.

The cutting force of the effector on the rock:

$$
F_{W}=m_{w, b} \cdot g \cdot \mu \cdot \rho,[N]
$$

where $\rho$ - rock density; $\mu$ - coefficient of friction of the effector on the rock.

The idle working time is calculated as the time from the motor start to the arrival at the operating area and back after completion of work:

$$
t_{n \cdot l}=\frac{L_{s}}{V_{\text {harv }}},[\mathrm{min}]
$$

where $L_{s}$ is the distance from the parking area to the face; $V_{\text {har }}$ is the average travel speed of the combine.

The on-load working time of the combine is equal to:

$$
t_{w}=\frac{S_{p} \cdot Q_{w \cdot b} \cdot \rho \cdot 10^{3}}{V_{w \cdot b} \cdot m_{w \cdot b}},[\mathrm{~min}]
$$

where $S_{p}$ - is the roadway area; $V_{w . b}$ is the rotational speed of the combine's effector.

Cycle time:

$$
t_{c}=2 \cdot t_{n . l}+t_{w},[\min ]
$$

Equivalent force of the effector during operation: 


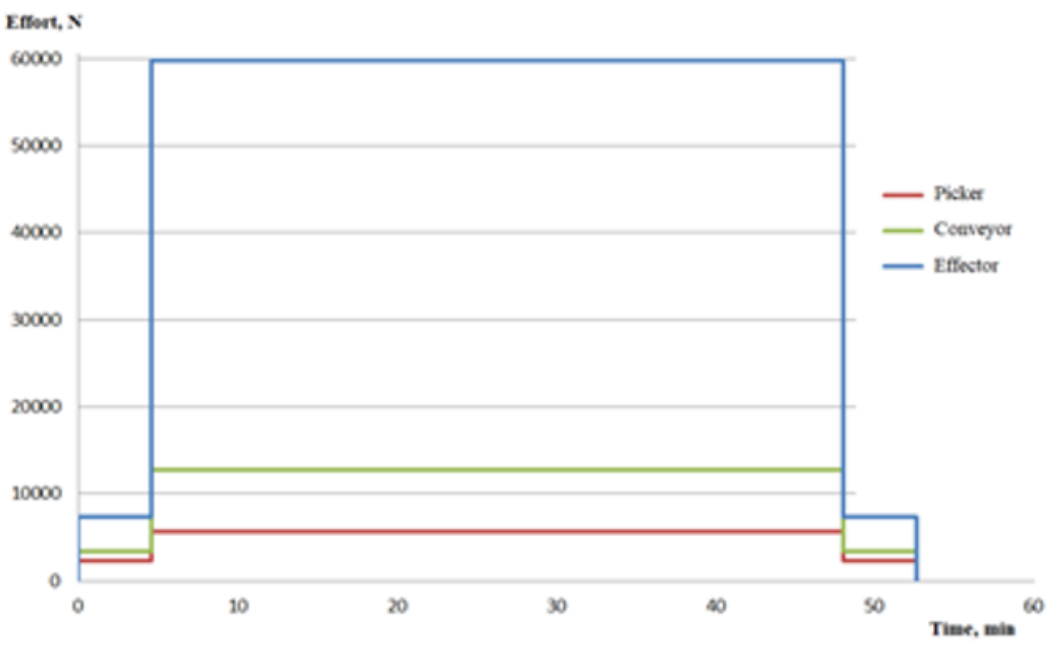

(a)

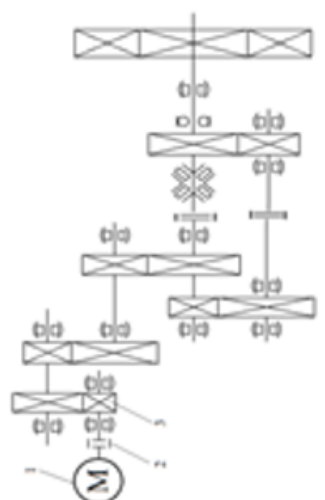

(b)

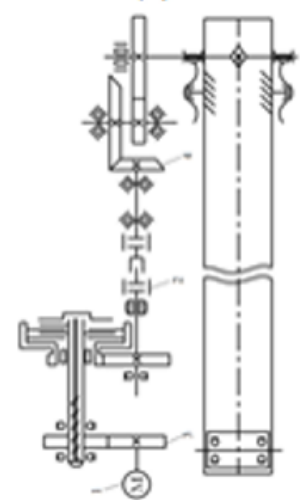

(c)

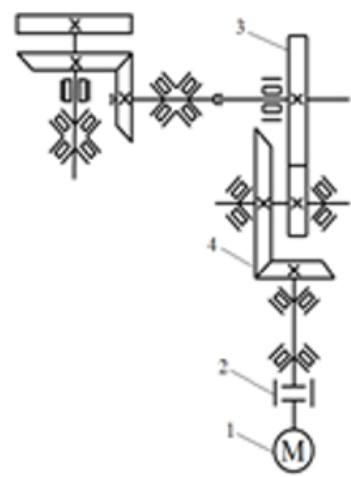

(d)

Fig. 1.Load diagrams of combine's mechanisms (a). Kinematic diagrams of electric drive systems of the combine: (b) effector; (c) conveyor; (d) picker: 1 - electric motor, 2 - clutch, 3 - cylinder gear, 4 - bevel gear.

$$
F_{e q}=\sqrt{\frac{2 \cdot\left(F_{n . l}^{2} \cdot t_{n . l}\right)+F_{w}^{2} \cdot t_{w}}{t_{c}}},[N]
$$

Preliminary motor power is calculated by the following formula:

$$
N=\frac{F_{e q} \cdot Q_{w \cdot b}}{V_{w \cdot b} \cdot 100 \cdot \eta},[W]
$$

where $\eta$ - is the efficiency of the mechanism.

Obtained motor power should be increased by 10 $15 \%$ to ensure reliability in case of potential overloads [16-18]. This power is called installed power:

$$
N_{\text {inst }}=(1.1 \div 1.15) \cdot N \cdot 10^{-3},[\mathrm{~kW}]
$$

Table 2.Calculated parameters of the combine mechanisms.

\begin{tabular}{|l|c|c|c|}
\hline \multirow{2}{*}{\multicolumn{1}{|c|}{ Parameter }} & \multicolumn{3}{|c|}{ Combine Mechanisms } \\
\cline { 2 - 4 } & Effector & Picker & Conveyor \\
\hline Effort at idle speed, $F_{n . l}[\mathrm{~N}]$ & 7350 & 2312 & 3372 \\
\hline Working effort, $F_{w}[\mathrm{~N}]$ & 59780 & 5685 & 12704 \\
\hline Equivalent force, $F_{e q}[\mathrm{~N}]$ & 54400 & 5209 & 11625 \\
\hline Idle time, $t_{n . l}[\mathrm{~min}]$ & 4.6 & 4.6 & 4.6 \\
\hline Working time, $t_{w}[\mathrm{~min}]$ & 43.4 & 43.4 & 43.4 \\
\hline Cycle time, $t_{c}[\mathrm{~min}]$ & 52.6 & 52.6 & 52.6 \\
\hline Preliminary power, $N[\mathrm{~W}]$ & 147800 & 29597 & 60549 \\
\hline Installed power, $N_{\text {inst }}[\mathrm{kW}]$ & 170 & 34 & 70 \\
\hline
\end{tabular}

The table shows that the most powerful mechanism the combine's effector - has the greatest ratio of operating and idling force. The cycle time of the combine is the same for all its mechanisms showing the time of stoping of one rock strip (by the width of the cutting bar) in the gravel face. Installed power shows the minimum power of electric motors of the mechanisms required to create the necessary force during operation. After calculations are completed the load diagrams for the mining combine's main mechanisms should be plotted (a).Kinematic diagrams of the effector of the combine (b), conveyor (c) and picker (d) are shown in Fig. 1. 
Based on the above calculations, asynchronous motors with a short-circuit rotor, which have the closest power values and are suitable in terms of voltage and operating mode, are selected from the catalogue. The models and technical parameters of electric motors are given in Table 3.

Table 3. Selection of electric motors of the combine mechanisms.

\begin{tabular}{|l|c|c|c|}
\hline \multirow{2}{*}{ Parameter } & \multicolumn{3}{|c|}{ Combine Mechanisms } \\
\cline { 2 - 4 } & Effector & Picker & Conveyor \\
\hline Electric motor brand & 4A315M4UZ & AIR200M4 & AIR250S4 \\
\hline $\begin{array}{l}\text { Shaft rotation axis } \\
\text { height, } h[\mathrm{~mm}]\end{array}$ & 315 & 200 & 250 \\
\hline Power, $P_{N}[\mathrm{~kW}]$ & 200 & 37 & 75 \\
\hline $\begin{array}{l}\text { Rated speed, } n_{N} \\
\text { [rpm] }\end{array}$ & 1480 & 1470 & 1478 \\
\hline Efficiency, $\eta$ & 0.94 & 0.925 & 0.94 \\
\hline Power factor, $\operatorname{Cos} \phi$ & 0.92 & 0.89 & 0.88 \\
\hline $\begin{array}{l}\text { Rated voltage, } U_{N} \\
\text { [V] }\end{array}$ & 1140 & 660 & 660 \\
\hline $\begin{array}{l}\text { Starting current to } \\
\text { rated current ratio, } \\
I_{S} I_{N}\end{array}$ & 6.0 & 7.5 & 7.5 \\
\hline $\begin{array}{l}\text { Starting torque to } \\
\text { rated torque ratio, } \\
M_{S} M_{N}\end{array}$ & 1.3 & 1.7 & 1.7 \\
\hline $\begin{array}{l}\text { Maximum torque to } \\
\text { rated torque ratio, } \\
M_{M a x} M_{N}\end{array}$ & 2.2 & 2.7 & 2.5 \\
\hline $\begin{array}{l}\text { Moment of inertia, } J \\
\left.\text { [kg } \mathrm{m}^{2}\right]\end{array}$ & 3.63 & 0.28 & 0.89 \\
\hline $\begin{array}{l}\text { Number of pole } \\
\text { pairs, } 2 p\end{array}$ & 2 & 2 & 2 \\
\hline
\end{tabular}

\subsection{Calculation and construction of static characteristics using reduced moments}

The construction of a load diagram and tachogram of electric motors requires the calculation of gear reduction ratio, reduction of static resistance moments and operating speeds to the motor shaft and taking dynamic moment and acceleration of electric motor, taking into account the overload capacity of the motor [19].

Rating, starting and maximum motor torque are determined by the following formulas:

$$
\begin{aligned}
& M_{N}=\frac{P_{N}}{\omega_{N}}, M_{S}=k_{S} \cdot M_{N}, \\
& M_{\text {Max }}=k_{\text {Max }} \cdot M_{N},[N \cdot m],
\end{aligned}
$$

where $k_{S}$ and $k_{\text {Max }}$ are the ratio of starting and maximum torque to rating torque (taken according to passport data).

Gear reduction ratio for each mechanism is determined by the formula:

$$
i_{p}=\frac{\omega_{N}}{V_{r} \cdot \pi} \cdot \frac{d}{2},
$$

where $\omega_{N}$ is the rated rotation speed of the motor, $\mathrm{rad} / \mathrm{s}$; $V r$ is the speed (rotation) of the mechanism, $\mathrm{m} / \mathrm{s} ; d$ is the diameter of the rotational mechanism, $\mathrm{m}$.
Static resistance moments reduced to the engine shaft at operating force and at idling speed, respectively, will be calculated as follows:

$$
M_{s w, 5 n \cdot l}=\frac{F_{w, n \cdot l} \cdot d / 2}{i_{p} \cdot \eta}+M_{N},[N \cdot m],
$$

where $\eta$ is motor efficiency; $F_{w, n . l}$ are working and idle forces, respectively, which are determined by formulas (5) and (6) of the previous section.

The total moment of inertia of the drive is determined by the formula:

$$
I_{\Sigma}=\delta \cdot J+m_{M} \cdot \frac{d^{2} / 2}{i_{p}},\left[\mathrm{~kg} \cdot \mathrm{m}^{2}\right],
$$

where $J$ is the moment of inertia of the motor, $\mathrm{kg} \cdot \mathrm{m}^{2} ; \delta$ is the coefficient that takes into account the moment of inertia of the clutches and the gearbox.

Obtain the dynamic moment of the motor according to the condition of maximum utilization of the motor by overload capacity:

$$
M_{\text {din }}=k_{P} \cdot\left(M_{M a x}-M_{S W}\right),[N \cdot m],
$$

where $k_{P}$ is a ratio that takes into account the overshoot of the moment on the corrected load diagram.

Acceleration of the motor shaft and the effector of the mechanism in transient modes can be found according to the following formulas:

$$
\varepsilon=\frac{M_{\text {din }}}{J_{\Sigma}}, \mathbf{a}=\frac{\varepsilon}{i_{p}},\left[\frac{\mathrm{rad}}{\mathrm{s}^{2}}\right]
$$

In order to draw the load diagram, divide it into 3 intervals. First, calculate the acceleration and deceleration intervals of the electric drive and the operating interval at a constant speed.

Determine the acceleration and deceleration time (1 and 3 intervals) and the values of moments in these intervals, using the following formulas:

$$
\begin{aligned}
& t_{1}=t_{3}=\frac{\omega_{N}}{\varepsilon},[s], M_{1}=M_{d i n}+M_{S n . l}, \\
& M_{3}=M_{d i n}-M_{S n . l},[N \cdot m]
\end{aligned}
$$

The duration of operation of electric motors with a constant speed will depend on the type of a mechanism, its mode of operation and technological conditions.

In the case considered, for a mining combine the technological process lies in stoping of the area, so the operating time will be determined as:

$$
t_{\mathbf{2}}=\frac{S_{p} \cdot Q_{M} \cdot \rho \cdot 10^{3}}{V_{r} \cdot m_{M} \cdot 60},[\mathrm{~min}]
$$

where $S_{p}$ is the roadway area, $\mathrm{m}^{2} ; Q_{M}$ is the mechanism capacity, $\mathrm{m}^{3} / \mathrm{min}$.

The motor torque during operation at a constant speed is equal to the static resistance torque at the 


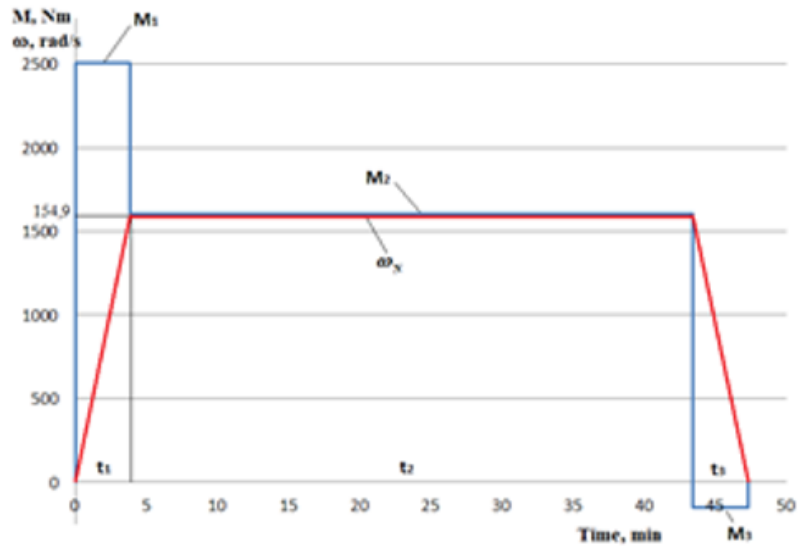

(a)

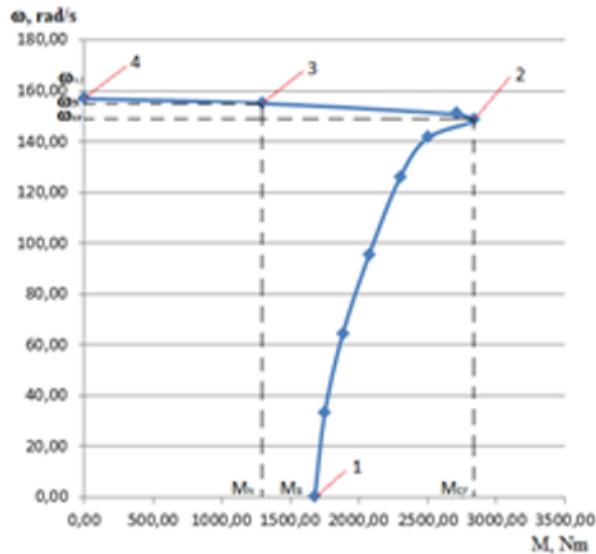

(b)

Fig. 2.Load diagram and tachogram (a) and mechanical characteristic (b) of the electric motor of the combine's effector.

operating force. In the case the following equality will be applied: $M_{\mathbf{2}}=M_{S w}[N \cdot m]$.

The authors will calculate and build a load diagram and tachogram for the most powerful electric motor of a mining combine - boom-type effector [20]. The result of the calculation and construction of the load diagram and tachogram is shown in Figure 2 (a).

Further, calculate and build the motor mechanical characteristic defined as the dependence of the angular speed of rotation $\omega$ on the electromagnetic moment of the motor $M$, i.e., obtain the function $f=\omega(M)$. For this purpose, the authors use the Kloss formula, setting the slip values from 0 to 1 and inserting it in the expression:

$$
M=2 \cdot M_{\text {Max }} \cdot \frac{1+a \cdot s_{c r}}{\frac{s}{s_{c r}}+\frac{s_{c r}}{s}+2 \cdot a \cdot s_{c r}},[N \cdot m],
$$

$$
\text { where } a=R_{s} / \mathrm{\Xi}\left(R \rrbracket_{r} \cdot k^{2}\right) \text {. }
$$

Similarly to the load diagram, calculate and build the mechanical characteristic for the electric motor of the combine effector. The obtained mechanical characteristic can be seen in Figure 2 (b).

There are four points on the graph, typical for an asynchronous motor: 1 - motor start torque (speed equals zero, torque takes starting value), 2 - critical operation mode (torque has maximum value, which should not be exceeded for the motor to start), 3 - typical operation (speed and torque have nominal values), 4 - ideal noload point (motor torque equals zero, rotor speed equals stator magnetic field rotation rate). Since the operating torque point does not exceed the value of the starting and critical moments, it can be assumed that electric motors were pre-selected correctly.

\section{Conclusion}

The calculations resulted in the construction of load diagrams and static characteristics of a multi-motor electric drive system of a mining combine using the methods of equivalent forces and reduced moments. Such studies are relevant for the diamond mining industry in Western Yakutia [21, 22]. Based on the calculated equivalent forces, the preliminary and installation capacities of electric motors were obtained and, subsequently, three-phase asynchronous motors with a short-circuit rotor were selected from the catalogue. The equivalent force method is suitable for rotational mechanisms showing a low absolute error between calculated and reference data. The static characteristics of pre-selected electric motors were built on the basis of calculated reduced moments. The characteristics confirm the correctness of preselection of motors. The calculations performed will be useful for further computer simulation of the operation of electric drive systems of a mining combine and power supply system of a mining site [23-25]. In the case considered, computer modeling is the only possible tool for further evaluation of power quality in the mine underground part not accessible for experimental research and physical measurements [26-30].

\section{Acknowledgements}

The paper was prepared in the framework of the competition of the Russian Scientific Foundation, project 20-79-10012 "Modeling of Electric Power Complexes and Systems Based on Theoretical and Experimental Research".

\section{References}

[1] V.A. Chanturia, S.S. Bondar, K.V. Godun, B.E. Goryachev, GornyiZhurnal 2, 55-58 (2015)

[2] V.A. Chanturia, K.V. Godun, Yu.G. Zhelyabovsky, B.E. Goryachev, GornyiZhurnal 3, 67-75 (2015)

[3] A.S. Chaadaev, I.V. Zyryanov, D.S. Kirillov, I.F. Bondarenko, GornyiZhurnal 11, 48-52 (2015)

[4] V. Hrinov, A. Khorolskyi, E3S Web of Conferences 60, 00017 (2018) 
[5] B.L. Talgamer, Y.G. Roslavtseva, IOP Conference Series: Earth and Environmental Science 229, 1, 012015 (2019)

[6] M. Cehlar, S.A. Zhironkin, O.V. Zhironkina, Bulletin of the Kuzbass State Technical University 3, 133, 94-102 (2019)

[7] G.I. Odnokopylov, V.A. Shevchuk, Y.N. Dementyev, Bulletin of the Tomsk Polytechnic University, Geo Assets Engineering 330, 5, 131140 (2019)

[8] Operating instructions AM 75/162, VOESTALPINE BergtechnikGes.m.b.H, A-8740 Zeltweg, AUSTRIA, 01-09-05

[9] E.K. Eshchin, Journal of Mining Institute 239, 570-575 (2019)

[10] Y. Liu, L. Hou, D. Qin, Y. Zhang, The International Journal of Advanced Manufacturing Technology 94, 9-12, 3553-3561 (2018)

[11] V.V. Okolnishnikov, A.A. Ordin, S.V. Rudometov, Optoelectronics, Instrumentation and Data Processing 55, 4, 383-387 (2019)

[12] K.N. Kopylov, S.S. Kubrin, I.M. Zakorshmenniy, S.N. Reshetniak, Ugol 3, 46-49 (2019)

[13] A.N. Egorov, A.S. Semenov, Y.S. Kharitonov, O.V. Fedorov, GornyiZhurnal 2, 77-82 (2019)

[14] Yu.V. Bebikhov, A.S. Semenov, I.A. Yakushev, N.N. Kugusheva, S.N. Pavlova, M.A. Glazun, IOP Conference Series: Materials Science and Engineering 643, 012067 (2019)

[15] Yu.V. Bebikhov, A.S. Semenov, M.N. Semenova, S.N. Pavlova, M.A. Glazun, N.K. Miftahova, E3S Web of Conferences 124, 03015 (2019)

[16] E.I. Gracheva, O.V. Naumov, Journal of Engineering and Applied Sciences 11, 13, 29342938 (2016)

[17] A.I. Fedotov, E.I. Gracheva, E.A. Fedotov, N.V. Chernova, Journal of Engineering and Applied Sciences 11, 13, 2939-2945 (2016)

[18] E.I. Gracheva, O.V. Naumov, A.N. Gorlov, IOP Conference Series: Materials Science and Engineering 643, 1, 012060 (2019)

[19] A.N. Egorov, A.S. Semenov, Yu.V. Bebikhov, A.A. Sigaenko, International Journal of Energy for a Clean Environment 20, 2, 153-165 (2019)

[20] A.N. Egorov, Y.S. Kharitonov, V.A. Shevchuk, A.S. Semenov, Bulletin of the Tomsk Polytechnic University, Geo Assets Engineering 331, 6, 141151 (2020)

[21] N.S. Volotkovskaya, N.N. Kugusheva, A.S. Semenov, I.A. Yakushev, S.N. Pavlova, O.V. Kolosova, E3S Web of Conferences 124, 04001 (2019)

[22] N.S. Volotkovskaya, A.S. Semenov, O.V. Fedorov, IOP Conference Series: Materials Science and Engineering 753, 8, 082033 (2020)

[23] A.S. Semenov, V.M. Khubieva, Y.S. Kharitonov, Mathematical modeling of static and dynamic modes DC motors in software package MATLAB, in 2018 International Russian Automation Conference, RusAutoCon 2018, New York, Curran Associates, 8501666 (2018)

[24] A.S. Semenov, A.N. Egorov, V.M. Khubieva, Assessment of energy efficiency of electric drives of technological units at mining enterprises by mathematical modeling method, in 2019 International Conference on Industrial Engineering, Applications and Manufacturing, ICIEAM 2019, New York, Curran Associates, 8743025 (2019)

[25] A.S. Semenov, M.N. Semenova, Y.V. Bebikhov, Development of Universal Mathematical Model of Electrical Power Supply System of Area of Industrial Enterprise, in Proceedings - 2019 International Russian Automation Conference, RusAutoCon 2019, New York, Curran Associates, 8867704 (2019)

[26] N.M. Kuznetsov, A.S. Semenov, Yu.V. Bebikhov, A.V. Rybnikov, GornyiZhurnal 1, 23-26 (2014)

[27] A.S. Semenov, N.M. Kuznetsov, Measurement Techniques 57, 4, 417-420 (2014)

[28] A.A. Shpiganovich, O.V. Fedorov, K.A. Pushnitsa, E.V. Churkina, Izvestiya Ferrous Metallurgy 60, 9, 726-731 (2017)

[29] Y.V. Shevyrev, O.V. Fedorov, A.S. Sarvarov, Mining Informational and Analytical Bulletin 3, 82-90 (2018)

[30] O.V. Fedorov, Expeditious forecasting of power consumption, in 2017 International Conference on Industrial Engineering, Applications and Manufacturing, ICIEAM 2017 - Proceedings, New York, Curran Associates, 8076221 (2017) 